\title{
Começar e, talvez, acabar... Inventar um corpo que escreve na formação de pesquisadores em educação
}

\author{
Begin and, perhaps, end ... Inventing a writing body in the formation of \\ researchers in education
}

Teresa N. R. Gonçalves

Universidade Federal do Rio de Janeiro

\begin{abstract}
RESUMO:
Neste artigo apresentam-se práticas de estudo em torno da leitura e da escrita como práticas de pesquisa, pensa-se como estas práticas constituem a pesquisa como espaço de interrogação e como através delas se vai inventando um corpo que escreve na formação de professores. A questão central é: como se cria um espaço em que este corpo possa se constituir? Para responder a esta questão, explicitam-se entendimentos de leitura e escrita, suas relações e as condições para que elas aconteçam na sala de aula a partir de movimentos produzidos na formação de pesquisadores em educação. A partir de Barthes, Foucault, Anzaldúa, Prado Coelho ou Murakami discute-se a possibilidade de experimentação de uma física da leitura e da escrita no campo da pesquisa em educação e suas implicações, apresentando alguns elementos que compõem as práticas apresentadas.
\end{abstract}

Palavras-chave: formação de professores; pesquisa em educação; leitura; escrita.

\begin{abstract}
:
In this article, study practices around reading and writing are presented as research practices, it is thought how these practices constitute research as a space for interrogation and how through them a writing body in teacher education is invented. The central question is: how to create a space in which this body can be constituted? In order to address this question, reading and writing understandings, their relations and the conditions for them to happen in the classroom are explored through movements produced in the formation of researchers in education. Inspired by Barthes, Foucault, Anzaldúa, Prado Coelho or Murakami, the possibility of experimenting with a physics of reading and writing in the field of educational research and its implications are discussed and some elements that constitute these practices are presented.
\end{abstract}

Key-words: Teacher Education; Educational Research; Reading; Writing.

DOI: 10.12957/mnemosine.2020.52685

\section{Começar}

No texto "Começar e Acabar", Italo Calvino (1998) começa por nos falar do momento crucial de começar a escrever um romance, em que estão abertas todas as possibilidades, de dizer tudo, de todos os modos possíveis, mas em que precisamos dizer 
alguma coisa de um modo particular. Calvino (1998: 149) fala desse "momento decisivo para o escritor: a separação da potencialidade ilimitada e multiforme para encontrar uma coisa que ainda não existe mas que só pode existir aceitando limites e regras”. Esse início é o momento de separação da "multiplicidade dos possíveis" e marca "a entrada num mundo completamente diferente: um mundo verbal" (CALVINO, 1998: 150). O texto vai analisando diferentes exemplos de inícios (resenha de inícios) em autores da literatura universal, para mais adiante se centrar em exemplos de finais (resenha de finais) começar e acabar...

Calvino termina com o exemplo de uma das últimas peças de Samuel Beckett Improviso do Ohio. Diz Calvino, descrevendo a peça de Beckett:

Dois velhos idênticos de compridos cabelos brancos, vestidos com longos gibões pretos, estão sentados a uma mesa. Um tem na mão e lê um livro muito gasto. O outro ouve calado, e às vezes interrompe-o com uma batida dos nós dos dedos na mesa. 'Litle is left to tell' [Pouco resta para dizer], e conta uma história de luto e solidão de um homem que deve ser o homem que ouve aquela história até à chegada do homem que lê e relê aquela história, lida e relida sabe-se lá quantas vezes até à frase final: 'Litle is left to tell', mas talvez reste sempre ainda qualquer coisa à espera daquela frase. Talvez pela primeira vez no mundo haja um autor que conte o esgotar de todas as histórias. Mas por mais esgotadas que estejam, por pouco que tenha restado para contar, ainda se continua a contar. (CALVINO, 1998: 167)

O começar e, talvez, acabar, de que trata este texto é o do trabalho em torno da leitura e da escrita na pesquisa em educação e na formação de professores. Este começar na pesquisa em educação, "que só pode existir aceitando limites e regras", como diz Calvino (1998: 149), através de exercícios de leitura e escrita, e este acabar interrogado, em que as leituras, as escritas, não terminam, "por mais esgotadas que estejam, por pouco que tenha restado para contar, ainda se continua a contar" (CALVINO, 1998: 167). Começar, acabar, ler, escrever em meio a "uma poeira de possibilidades que se agregam e desagregam" (CALVINO, 1998: 166).

Inspirada pelas palavras de Calvino, proponho, não só pensar práticas de estudo em torno da leitura e da escrita como práticas de pesquisa, mas também, pensar como estas práticas constituem a pesquisa como espaço de interrogação, como através delas se vai inventando um corpo que escreve na formação de professores. Um corpo que se constitui neste entre, o começar e o acabar interrogado, na abertura constituinte da pesquisa em educação a partir da experiência da leitura e da escrita, como possibilidade de instaurar um espaço de liberdade em que as possibilidades da pesquisa na universidade possam ser reinventadas, em que modos outros de ler e de escrever em conjunto possam 
ser experimentados. A questão que me move é: como se cria um espaço em que este corpo possa se constituir? Para responder a esta questão tratarei de explicitar o que entendo por leitura e escrita e suas relações e quais as condições para que ela aconteça na sala de aula a partir dos movimentos produzidos na formação de pesquisadores em educação que venho ensaiando.

Inspirada por Barthes, Foucault, Anzaldúa, Prado Coelho ou Murakami, argumentarei pela possibilidade de experimentação de uma física da leitura e da escrita no campo da pesquisa em educação e suas implicações, através da discussão de determinadas práticas de leitura e escrita, das relações e condições que se estabelecem a partir delas na sala de aula e da figura de um escritor-leitor-pesquisador-professor que emerge dessa experimentação. Face a uma microfísica do poder da escrita e da leitura como instrumentos de produção de subjetividades e saberes dóceis, úteis, instrumentais, proponho a exploração da possibilidade de ensaiar uma física da leitura e da escrita na pesquisa em educação e na formação de professores que opere a partir da partilha do incômodo, do deslocamento dos modos instituídos de relação com a leitura e a escrita na universidade.

\section{O convite}

No início do semestre, a professora apresenta as questões que estariam na base da disciplina de pesquisa em educação do curso de pedagogia: a partir da leitura, análise e discussão de temas e questões relacionados com a pesquisa em educação, seus princípios e procedimentos, pretende-se promover a identificação, reflexão e problematização dos modos vigentes de entender e fazer pesquisa no campo da educação e as questões que se colocam ao pesquisador iniciante, assim como pensar possibilidades emergentes neste campo. Os modos de fazer pesquisa em educação tendem a ser naturalizados sem que se compreendam a sua origem, pressupostos e implicações históricas, epistemológicas e sociais; daí a necessidade de abrir espaços de reflexão e debate que permitam pensar alternativas, pluralizando entendimentos sobre os modos de pensar e fazer a pesquisa em educação. O curso será focado no exercício da leitura e da escrita como prática de pesquisa e pretende ser um espaço de experimentação e discussão de propostas de pesquisa elaboradas pelos alunos.

Os conteúdos, a matéria a ser trabalhada, tal como este texto, são inspirados no texto do Italo Calvino (1998) “Começar e acabar”. O curso será dividido em 3 partes: $I$. Começar: O estudo, A escrita, A pesquisa, Instruções para iniciantes; II. Implicar-se: A 
escrita de si como experiência de pesquisa, A pesquisa como relação com a alteridade, Modos de fazer pesquisa; III. Acabar: Projetar e projetar-se na pesquisa em educação; Tornar públicas as experiências de pesquisa, $\mathrm{O}$ futuro da pesquisa em educação, entre tradições e possibilidades: algumas linhas de fuga. Este texto parte desta mesma estrutura, embora acabe com uma interrogação - no acabar -, pois um curso acaba, uma pesquisa acaba, mas a leitura e a escrita não têm fim.

A professora apresenta também os textos a serem lidos, assim como as chaves do curso, ou dos exercícios de leitura que propõe: textos de filosofia, de literatura, de pedagogia, fragmentos de filmes. Estes textos se constituem como uma polifonia, uma multiplicidade de vozes que procuram escapar às obviedades do campo e criam um arquivo a partir do qual lemos, escrevemos e pensamos juntos a pesquisa em educação. Este arquivo, ao contrário dos princípios modernos da ordem e da acumulação, existe na tensão e no trânsito, como um amontoado que simultaneamente nos junta e nos envia para fora de nós mesmos, que nos aproxima de uma alteridade que ao mesmo tempo nos une e nos fragmenta, nos aproxima e distancia, abrindo um outros espaço e um outro tempo em que seja possível pensar a leitura-escrita na pesquisa em educação (ANDRADE et al., 2018).

Os textos produzem deslocamentos que nos permitem ensaiar outras formas de relação com a leitura, com a escrita, com a pesquisa que não as que comumente estão associadas seja à escrita acadêmica, seja à pesquisa em educação. Ensaiar essas relações outras no processo de pesquisa implica uma mudança na forma como estas práticas são trabalhadas na formação de professores, principalmente nas disciplinas relacionadas com a pesquisa em educação. A um entendimento da leitura e da escrita como uma determinada fase do processo de pesquisa, ao serviço de uma lógica explicativa, apresentativa e comunicativa, em que os dados empíricos aparecem como centrais, se contrapõe a possibilidade de trabalhar a leitura e a escrita como constitutivas do processo de pesquisa, no sentido em que implicam uma relação transformativa entre sujeito e objeto. Numa tal relação, estes se estilhaçam para se (re)constituírem mutuamente no próprio processo de pesquisa. A partir desta hipótese, podemos experimentar a multiplicidade de possibilidades que se abrem para o trabalho com a leitura e a escrita na formação de professores e pesquisadores em educação. Face à perspectiva de uma leitura que precede e uma escrita que sucede aos dados, à empiria, entendida como o cerne da 
pesquisa, uma leitura e uma escrita como pesquisa, que acompanham, constituem, transformam e reconstituem a pesquisa - uma leitura e uma escrita como pesquisa.

Por isso, lemos "Primeira Carta" de Bruno Latour (2016); "Começar e acabar" de Italo Calvino (1998); "De que eu falo quando falo de corrida" de Haruki Murakami (2018); “Os estudantes" de Agamben (2017); "Pensamento, corpo, devir. Uma perspectiva ético/estético/política do trabalho acadêmico" de Suely Rolnik (1993), "Experiência e alteridade em educação" de Jorge Larrosa (2011); ou vemos o filme "Onde jaz o teu sorriso?" de Pedro Costa (2009). No espaço da aula, estudantes e professora leem textos em conjunto, comentam, conversam sobre esses textos e sua relação com a pesquisa em educação e com os processos de leitura e escrita vigentes na academia. Ensaiam-se leituras, partilham-se leituras, experimentam-se escritas, partilham-se escritas.

Começamos por ler uma carta - Bruno Latour (2016) -, discutimos forma e conteúdo (uma carta é um formato 'acadêmico?; podemos trabalhar conteúdos científicos a partir de uma carta? Que outros formatos podemos usar?); escrevemos sobre nossa relação com a escrita (a partir de Murakami); escrevemos um memorial (a partir de Suely Rolnik, pensando nossos interesses de pesquisa a partir da escrita das marcas); escrevemos um projeto de pesquisa a partir do memorial e da escrita de si; assistimos ao filme "Onde Jaz o teu sorriso?" de Pedro Costa, para pensar a pesquisa como montagem; endereçamos cartas aos estudantes por vir...

Os estudantes escrevem a partir dos textos lidos. Escrevem textos curtos a partir das leituras e inquietações que despertam, escrevem cartas, memoriais, projetos de pesquisa. Professora e estudantes discutem cada semana os textos escritos. A professora lê e comenta, os colegas leem e comentam, e a cada semana cada um vai reescrever o seu texto a partir das leituras, dos comentários e da conversa em torno do texto que se desenrolou na aula. Experimentam-se estilos e formatos de escrita - a escrita de si no memorial, a escrita acadêmica no projeto de pesquisa, a carta, o texto longo, o texto curto -, ensaiam-se composições a partir dos diferentes modos da escrita e seus usos. Há olhares, comentários, gestos, inquietações, desconfortos, resistências, entusiasmos, estranhamentos no ar.

Há um desconforto inicial com os textos, as escritas, os formatos e modalidades de leitura propostos, com os dispositivos que diferem das formas acadêmicas mais comuns - o texto científico, a escrita acadêmica. Ensaiamos modos coletivos de experimentar a pesquisa através de exercícios de leitura e escrita que funcionam num 
duplo movimento, de desfamiliarização em relação a modos habituais de pensar, a praticar a leitura e escrita acadêmicas através da experimentação de modos outros de ler e escrever que não estão dados à partida, mas que, antes, se vão construindo no próprio processo de experimentação em conjunto de diferentes formas e possibilidades de leitura e escrita. Trata-se de performar práticas investigativas assentes no gesto de ler e escrever que acompanhem os traços que esse gesto vai deixando nas subjetividades, num caminho sensível de variação contínua (INGOLD, 2019), que se compõe num gaguejar comum, em comum, numa gagueira criadora, de exercitar os começos e abrir os fins a novos começos, uma forma de começar pelo meio (DELEUZE, 1997).

\section{A leitura}

O que faz aquele que lê? O que faz aquele que dá a ler? O que faz com que a leitura aconteça na sala de aula?

Trata-se, antes de mais, daquilo que Eduardo Prado Coelho (2001), num texto comentário a um poema de Manuel Gusmão, chamou de uma física da leitura, que contempla tanto "um processo mental de inscrição e osmose no corpo", como "a esforçada ginástica daquele que trabalha o corpo para o ato de ler" (CELHO, 2001: 80) ler é um processo de mobilização geral do corpo. Para Eduardo Prado Coelho (2001: 78), aquele que lê é aquele que "coloca o corpo na posição exata para ler". A posição exata não é a posição certa, não é uma posição específica, mas tem a ver com as condições que permitem a cada um a concentração necessária para adentrar-se no exercício da leitura. "Ler pode ser também escolher a posição certa para ler, partindo de um conjunto de protocolos que criam a disposição para a leitura" (Coelho, 2001: 78), essa posição é uma disposição. Na disciplina de que falo, trata-se, portanto, de colocar em posição esta disposição, para que a leitura possa acontecer. Esta leitura implica que o leitor é tomado pelo discurso, é uma leitura encarnada: provocada por um incômodo, um deslocamento produzido na relação do leitor com o texto.

Colocar-se em posição para ler a partir de um estado de abertura, exaltação, leveza ou desconforto que nos permita entrar lentamente no mundo ao mesmo tempo familiar e desconhecido da palavra escrita. Numa sala de aula, num determinado curso, colocamos o corpo na posição exata para ler, criamos as condições para que a leitura aconteça.

Começamos por apresentar o curso, os textos - agora precisamos trabalhar as regras da leitura, os protocolos que criam as disposição para a leitura: ler, sublinhar, 
anotar, trazer as anotações para discutir na aula, reler trechos junto com os colegas na aula, ler em conjunto, pensar em conjunto, levantar questões, pensar como cada texto se relaciona com os textos anteriores da disciplina, de outras disciplinas, do que aprendemos sobre pesquisa, sobre estudo, sobre educação, ligar o texto com outros textos e com o que está fora do texto - como um corpo sem órgãos (DELEUZE, 1992) -, com questões e interesses de pesquisa, escrever um memorial, escrever um projeto.

Ao mesmo tempo que empreender essa "esforçada ginástica daquele que trabalha o corpo para o ato de ler" (COELHO, 2001: 80) é uma tarefa, um modo de produção, é também aquilo que estilhaça essa mesma tarefa, o que irrompe como acontecimento que coloca o leitor em face do abismo do intempestivo, do imprevisível, do paradoxal da leitura. Não se trata, por isso, de uma metodologia, de uma técnica da leitura, mas sim “de uma experiência, que é ao mesmo tempo uma experiência dos limites dessa experiência - precisamente aí, no limite em que o acontecimento acontece, no seu estatuto absolutamente incalculável, irredutível e insubordinado em relação a qualquer método." (COELHO, 2001: 80). Ler é um processo de mobilização geral do corpo para ocupar, hesitante e cautelosamente, o espaço literário, que é, simultaneamente, um abrir-se do mundo, um abrir-se ao plural do mundo.

Quem dá a ler (LARROSA, 1999) dá também uma série de procedimentos de leitura: ler o texto uma vez em casa, sublinhar, trazer questões sobre o texto, escrever um texto sobre o texto lido a partir de um determinado conceito ou questão, refazer o texto escrito a partir da discussão das várias leituras na aula. Ler, reler, escrever, rees-crever. Estes são os movimentos de quem coloca o corpo na posição exata para ler na disciplina de pesquisa em educação. O texto faz com que a leitura aconteça na sala de aula, a aula decorre em torno do texto. Trazemos questões, destacamos trechos, lemos, relemos. A aula se torna uma comunidade de leitores incertos que tropeçam nas palavras, embrulham as sílabas, exercem, no modo vulnerável de desemaranhar os textos, o seu direito de eleger, o seu direito de ler (porque aquele que lê é aquele que escolhe, ler é eleger).

Para além da leitura individual, do ato solitário que implica, para além da atenção, uma certa reclusão, um certo isolamento como condições que tornam a leitura possível, trata-se também, na sala de aula, depois de uma primeira leitura individual, de um exercício coletivo (ler é também "reunir", "colecionar", fazer a coleta) de leitura que acontece em torno a estes textos incômodos, excêntricos, que deslocam, que transformam e, portanto, nos formam. Uma relação se vai construindo na turma através da leitura dos textos, num movimento que pretende preservar as marcas da experiência individual e, a 
partir delas, construir uma relação no grupo em torno do texto, de uma certa relação com a leitura. O texto é o comum. A relação com os textos - o texto publicado e o texto em andamento, seja o próprio ou o alheio - assenta numa dimensão relacional que procura manter a abertura do pensamento através de modalidades de troca que permitam desmultiplicar o conhecimento, escapando da replicação de modelos pré-definidos, dos modos e verificação e avaliação vigentes na universidade.

Ler é aceitar o jogo, é entregar-se ao prazer da leitura, criar um espaço de fruição, um espaço de possibilidade, de imprevisão, de desejo, em que "os dados não estejam lançados, que haja um jogo" (BARTHES, 1987: 9). O leitor é esse corpo que se coloca em posição de ler, um corpo que precisa ser inventado através da experiência da leitura, do embate entre as diferentes posições ocupadas pelo leitor e pelo texto. É nesse entre que se dá a leitura, como uma proposição existencial perpassada pelo incômodo, o prazer e o gozo, que passa pela inscrição, pela tatuagem desse evento no corpo. A leitura é o espaço de inscrição dessa tensão entre leitor e texto. Assim exercitada, ela implica um afastamento das verdades instituídas, das formalizações que compõem as tendências totalizantes, em prol da indeterminação, da heterogeneidade instaurada pela relação entre leitor e texto, privilegiando as linguagens excêntricas que abrem a pluralidade do texto, que operam nessa tensão. Daí a escolha de textos que escapam à lógica da apropriação e da totalização.

À suposta neutralidade da linguagem dos textos ditos científicos se contrapõem textos que operam a partir de um 'plural irredutível', que procuram escapar aos modos convencionais de relação com a leitura na universidade. Por isso, a leitura é escritura, o leitor é um escritor que, na sua escrita, opera a partir desta tensão entre si e o texto; é na escrita, entendida como escritura ${ }^{1}$, que esse encontro se inscreve através dos estranhamentos, apropriações, suspensões, prolongamentos e ruturas entre os diferentes universos. Por isso, a reação dos estudantes aos textos propostos é, frequentemente, de estranhamento, incômodo, desassossego: “que texto é este?”; “isto é um texto científico?", "pensei que tinha lido o texto errado!"; "gostei do texto, embora não saiba se compreendi o seu sentido!”.

Esta leitura implica uma relação outra com aquilo que não se entende e que não é da ordem do sentido ou da explicação, mas de uma afetação que opera na corporeidade leitora - o prazer, o gozo, emergem tanto da assimilação, como da divergência, da rejeição ou até do esquecimento presentes no processo de ler. Barthes (2004a) se refere a este gozo 
como o contrário do tédio, da redução da leitura a simples consumo, quando se ignora a relação de alteridade que o texto instaura, quando se ignora a condição do outro e se nega qualquer universo que seja alheio ao já conhecido. O tédio é a negação do jogo que desfaz o texto, do poder da linguagem que liberta os sentidos e intensifica a experiência.

Nesse sentido, a leitura não é reconhecimento ou contaminação, mas transmutação de sentidos, emergência, exploração, proposição existencial: "ler é fazer o nosso corpo trabalhar (sabe-se desde a psicanálise que o corpo excede em muito nossa memória e nossa consciência) ao apelo dos signos do texto, de todas as linguagens que o atravessam e que formam como que a profundeza achamalotada das frases." (BARTHES, 2004b:29). Assim experimentada, a leitura é infinita, é o lugar onde "a estrutura se descontrola" (BARTHES, 2004a: 42), onde os códigos, as ideologias, as estruturas históricas e culturais se deslocam num movimento que faz e desfaz a consistência do eu, do sujeito, que implica simultaneamente o conforto, o à-vontade - o prazer - e a dispersão e o desvirtuamento - o gozo. Este movimento faz do eu o outro ou vice-versa, em que o leitor "é sujeito que depressa se encontra na sua estrutura própria, individual: ou desejante, ou perversa, ou paranoica, ou imaginária ou neurótica (...)” (BARTHES, 2004a: 42).

\section{Implicar-se}

Este modo de implicação com a leitura-escritura pressupõe, ao nível da formação de professores, aquilo a que Jorge Larrosa (2018) chama a passagem da condição de aluno, como condição puramente administrativa, à condição de estudante. Trabalhar com a possibilidade de transformar o aluno em estudante implica, para Larrosa (2018), passar de uma condição institucional e posicional a uma condição existencial e pedagógica, assente na disposição para ler. Ou seja, trata-se de inventar formas de desalunizar os alunos para que eles possam viver, experimentar a sua condição de leitores entendida neste sentido, do estudo e não da aprendizagem - praticar uma atenção tensionada até ao limite, um recolhimento, uma ameaça, uma espera sem promessa -, para além dos dispositivos de profissionalização. Essa entrega, que caracterizaria o estudante, implica uma suspensão das conclusões, dos resultados, das respostas definitivas, para problematizar os discursos e práticas dominantes, problematizar-se, operar na provisoriedade dos significados, das respostas, das soluções. Inventar uma formação em que a experiência do leitor-estudante seja possível é uma questão que se coloca quando a lógica da profissionalização coloca a formação como função (social, política, 
profissional, cultural, económica) e não como forma (de separação de tempos, espaços e atividades).

Por isso, não se trata da aplicação de um método, de resultados ou de respostas, de normalização disciplinar ou de poder institucional, mas de estudo entendido como experimentação paciente, abertura ao intempestivo pela suspensão do tempo produtivo e das demandas sociais (INGOLD, 2018; MASSCHELEIN e SIMONS, 2013). A lógica do estudo não é, por isso, uma lógica da utilidade, mas uma lógica da suspensão, da inutilidade. O estudo é transformação e não aprendizagem (BIESTA, 2013), treino ou profissionalização; está sempre recomeçando, é, muitas vezes, difícil e perturbador. É libertador na medida em que desafia preconceitos e pressupostos, inquieta o pensamento.

Considerando a leitura como dispositivo na formação de professores, que tem funcionado como um instrumento de subjetivação, de produção de um sujeito, através de um conjunto de práticas, de saberes, de medidas e regras que orientam a relação com a leitura, capturando gestos, condutas, discursos de estudantes e professores na sua relação com o texto, a leitura e a escrita, a questão que se coloca neste ponto é: como colocar em jogo a leitura como contradispositivo? Como libertar o que foi capturado por estas práticas e saberes para o restutuir ao uso comum, para voltar a reunir o que foi separado? Como empreender esse movimento de profanação de que nos fala Agamben (2009), de restituir a leitura (e a escrita) ao uso comum? Como poderemos nos implicar num movimento de resistência que nos permita inventar um contradispositivo, que é uma resistência aos modos de saber e poder instalados na universidade, aos modos vigentes de atrelar a formação de professores e a pesquisa à verdade, à ciência, aos 'saberes tristes' e ligá-lo ao estudo?

Implicar-se significa entrar no jogo, habitar a experiência da leitura (e da escrita) como "algo do qual saímos transformados" (FOUCAULT, 2016), como uma experiência transgressora. Podemos pensar esse valor experiencial da leitura (e da escrita) relacionando-o com os dois usos da experiência em Foucault: restituição da contingência histórica das nossas experiências pessoais ou coletivas para mostrar que essas condições são transformáveis (os saberes, dispositivos, subjetividades, territórios e espaços) e aquilo que permite escapar a essas condições através de uma modificação, de uma transformação de si (transposição do limite, transgressão) (LAVAL, 2018). Este sentido de experiência opera por descontinuidades, rupturas, mutações. É resistência, recusa, desobediência (em relação ao poder, às disciplinas, às normas) que opera por uma prática de si que nos 
transforma relativamente ao que somos, ao que fizemos de nós mesmos, ao que dizem que devemos ser. A experiência é inseparável da possibilidade de transformação e essa possibilidade está intimamente ligada a práticas de liberdade que são tanto os motores dos deslocamentos históricos como os vetores das transformações subjetivas (LAVAL, 2018).

Pensar a leitura (e a escrita) como prática de liberdade na universidade implica pensá-la como esse deslocamento para um espaço outro, um espaço heterogéneo, onde a ordem das coisas não pára de ser perturbada pela ordem do discurso. O corpo é esse movimento que atravessa o espaço e é ele mesmo atravessado por intenções e desejos. É ele que permite escapar ao poder, contestar esse poder, e é nele que se inscreve a atitude crítica que acarreta a experiência de si mesmo como outro que estilhaça a ideia de domínio, de completude, de identidade fixa. O corpo que lê é aquele que vive a experiência radical de alteridade da qual emerge a atitude crítica inscrita no desejo do corpo de ser outro daquilo que dizem os saberes e que querem fazer os poderes, da vontade de viver de outro modo e do desejo de pensar de outro modo. Nesse sentido, o leitor-escritor seria um experimentador tal como Foucault se define a si próprio: "Eu sou um experimentador no sentido em que eu escrevo para mudar a mim mesmo e não mais para pensar a mesma coisa que antes.” (FOUCAULT, 2013: 290).

Por isso, o livro, tanto para o autor como para o leitor, é uma experiência de transformação da relação com o saber. O livro-experiência, para Foucault, é qualquer coisa de que se sai transformado, tanto da perspectiva do autor como do leitor, porque a leitura como experiência requer "o máximo de intensidade e, ao mesmo tempo, de impossibilidade" (FOUCAULT, 2013, p. 291), que arranca o sujeito de si próprio, é uma empreitada de dessubjetivação que Foucault encontra em autores como Nietzche, Blanchot e Bataille.

Não se trata, por isso, da constatação de uma verdade através da leitura dos textos e autores que são colocados em cima da mesa, mas de uma experiência para aquele que lê. O que importa é a experiência que o texto permite fazer e essa experiência, como diz Foucault, "não é verdadeira nem falsa", porque "uma experiência é sempre uma ficção" (FOUCAULT, 2013: 293). E assim como Foucault afirma que os seus livros não contêm “ensinamentos", também na aula de pesquisa educacional a experiência da leitura (e da escrita) não está ligada ao emprego nem de um método generalizável, ou à demonstração de uma teoria, mas a convites, a gestos feitos em público, como afirma o próprio Foucault em relação aos seus livros. 
Ler textos excêntricos implica um movimento de confiança para seguirmos o que não entendemos de imediato e assumir o risco do desconhecido. Seguir a interrogação essencial colocada pela leitura - "Quem sou agora? Tudo ficará assim movediço e errático". (COELHO, 2001: 82) Por isso, a leitura é tatuagem, a letra sobre o corpo, a inscrição na carne da experiência da leitura. Por isso, o leitor é um corpo exposto à marca da escrita, uma superfície vibrante e a leitura uma experiência de fronteira entre o eu e o outro. É, simultaneamente, o lugar "onde tudo se identifica" e o lugar onde "a identidade é desde sempre a identidade de um outro: um tu, uma transformação, um mundo possível" (COELHO, 2001: 85)

Daí que precisamos criar tanto na aula como na relação com a leitura, que vai para além dela, uma outra temporalidade, abrir um espaço tempo para que o estudo seja possível. “A leitura cria o seu próprio tempo, que é feito da distorção de todos os tempos conhecidos (...). Mais: a leitura passa a ser o relógio, é ela o instrumento de medição do tempo, uma hora de leitura, vinte horas de leitura, vinte anos depois." (COELHO, 2001: 81), “A leitura é uma máquina do mundo que se acelera pela paciência de uma desmedida lentidão.” (COELHO, 2001: 82). Praticar esta paciência e esta lentidão, experimentar a leitura como sentimento de vazio enquadrado.

A leitura exige uma casa, encasula e protege, mas também abre um espaço de ameaça - exercícios de leitura, uma casa para a leitura, a aula como casa da leitura. Dessa casa "se parte sempre de uma terra firme para uma terra movediça (do conhecido para o desconhecido), mas não há porto de chegada que não seja a indecidibilidade entre o que se move e o que no seu próprio movimento se imobiliza" (COELHO, 2001: 87-88) É uma viagem sem fim, toda a leitura é sem fim. "Talvez o lugar seja aqui e toda a partida um regresso, mas um regresso que não pode omitir o acontecimento que foi essa mesma partida, e por isso quando se regressa não se regressa nunca ao lugar de que se partira." (COELHO, 2001: 88).

Ler rompendo com todas as familiaridades, evitando todos os reconhecimentos, como referia Foucault (2016) relativamente à sua relação com os textos que serviam de base aos seus livros. Trata-se de estabelecer uma relação com o texto que opere nessa distância - medir a distância com aquilo que não somos, eis uma relação com a escrita que acolhe o desconhecido, o acontecimento, as marcas de um deslocamento para um espaço outro, um contraespaço, fora de toda a identificação, domínio, ou completude. O espaço da leitura, assim como o da escrita, torna-se um espaço heterotópico, um espaço 
de experimentação da heterogeneidade, de transformação da relação com o saber e de escape relativamente ao poder. O corpo é o que permite escapar ao poder, contestando-o.

Neste sentido, trata-se de uma perspectiva ético-política da experiência da leitura (e da escrita) que implica assumir uma atitude crítica, inscrita no movimento desse corpo que atravessa esse espaço, e que é atravessado por intenções e desejos, de ser outro, de viver de outro modo, de pensar de outro modo. Trata-se, portanto, de um processo de dessubjetivação que, arrancando o sujeito de si próprio, torna o leitor uma subjetividade em deslocamento e lhe permite estabelecer novas relações com as questões relacionadas com a pesquisa, com a educação, com a formação. Na aula, essa experiência está ligada a uma prática coletiva, a uma forma de ler, escrever e pensar que escapa à pura subjetividade, à individualidade, e é cruzada e atravessada por outros.

Pensar e fazer pesquisa a partir de textos-experiência, e não textos-verdade ou textos-demonstração, implica transgredir uma certa relação com a ciência predominante na formação de professores, e na universidade de um modo geral, entendida como produção de conhecimento, para perceber a ciência como uma prática que constitui simultaneamente sujeito e objeto de conhecimento. A história dessa gênese recíproca nos permite identificar como se vão construindo os discursos que definem tanto um domínio particular de objetos, como o lugar do sujeito ideal que pode conhecer esses objetos. Ou seja, "a verdade faz, ela própria, parte da história do discurso e é como um efeito interno em um discurso ou em uma prática" (FOUCAULT, 2013: 303), como tal, como pergunta o próprio Foucault: "Será que, no fundo, uma ciência não poderia ser analisada ou concebida como uma experiência, quer dizer, como uma relação tal que o sujeito possa ser modificado por essa experiência?" (FOUCAULT, 2013: 304).

Para Foucault, a diferença entre o saber e o conhecimento reside no facto de que enquanto este último é "o trabalho que permite multiplicar os objetos conhecíveis, desenvolver sua inteligibilidade, compreender sua racionalidade, mas mantendo a fixidez do sujeito que pesquisa." (FOUCAULT, 2013: 306), o saber é o "processo pelo qual o sujeito sofre uma modificação por aquilo mesmo que ele conhece, ou, antes, por ocasião do trabalho que efetua para conhecer. É o que permite, ao mesmo tempo, modificar o sujeito e conhecer o objeto." (FOUCAULT, 2013: 306). Implicar-se seria trabalhar a partir da possibilidade transformadora da leitura e da escrita na relação com a ciência e com a formação.

Os movimentos de leitura e de escrita que ensaiamos não se esgotam na aula, nem na disciplina, vão para além delas. Despoletamos processos de leitura e escrita que vão 
para além do espaço da sala de aula, são movimentos vitais, existenciais, éticos estéticos e políticos, movimentos transformadores do eu que reverberam como marcas nas subjetividades - daí a interrogação no acabar. Trata-se, através da leitura e da escrita numa aula de pesquisa em educação, de criar a possibilidade de estabelecer novas relações com o que está em questão - a leitura, a escrita, a pesquisa, a formação.

\section{A escrita}

Se existe uma física da leitura, ela se prolonga, se atualiza, numa física da escrita, uma ginástica que coloca o corpo na posição exata de escrever. "Se ler já era começar a escrever, escrever vai ser continuar a ler." (COELHO, 2001: 91). A questão é: “Donde, o leitor põe-se a escrever. E que escreve o leitor?" (COELHO, 2001: 91), mas também: como escreve o leitor? Como ele exercita a sua escrita?

No seu livro O que eu falo quando falo de corrida, o escritor Haruki Murakami (2018) escreve sobre a sua atividade de corredor, estabelecendo um paralelo entre correr e escrever, entre preparar-se para a correr a maratona e os seus processos de escrita. A escrita aparece associada ao movimento de endurance necessário para a corrida, um processo de resistência física que se obtém "aumentando tranquilamente a sua força de vontade" (MURAKAMI, 2018: 71), forçando-se a si mesmo "ao máximo dentro de seus limites individuais" (MURAKAMI, 2018: 73). Trata-se de um processo que não permite qualquer tipo de variação, implica rotina, repetição, como a escrita. "Se você precisa fazer parte do processo, tudo o que tem a fazer é transformar - ou talvez distorcer - a si mesmo mediante a repetição persistente, e tornar esse processo parte da sua própria personalidade" (MURAKAMI, 2018: 62). É uma escrita encarnada, que implica um processo de transformação do eu; essa transformação requer rotina, repetição e experimentação.

Existe, portanto, um duplo movimento: o exercício das regras, da rotina, e o ensaio, a experimentação com os estilos de escrita tensionando as formas da escrita acadêmica. Os exercícios de escrita que proponho pretendem criar as condições para exercitar esse endurance, preparar o corpo para se concentrar e perseverar na escrita, para a dificuldade que é, como diz Murakami (2018: 33), "ser capaz de sentar à minha escrivaninha, sem me preocupar com o tempo, e me concentrar em escrever", mas também criar um espaço de experimentação em que outras escritas sejam possíveis na academia. Os dois movimentos são interdependentes, não existem um sem um outro; a 
experimentação acontece a partir das regras definidas à partida, são elas que criam uma arena em que a experimentação pode acontecer - as regras que permitem começar (CALVINO, 1998) e os gaguejos que permitem crescer pelo meio (DELEUZE, 1997).

Para Murakami (2018), as duas qualidades mais importantes de um romancista são, para além do talento, a concentração - " a habilidade de focar todos os seus limitados talentos no que for mais crucial no momento" (p. 69) e a perseverança - a capacidade de persistir, de ficar o tempo suficiente numa atividade até ela se tornar um ato contemplativo, meditativo, um hábito natural, "sentir dor é uma realidade inescapável, mas continuar ou não suportando é algo que cabe ao corredor.” (MURAKAMI, 2018: 8), trata-se de despender tempo e esforço.

Murakami estabelece um paralelismo interessante entre estas atividades e a respiração:

Se a concentração é o processo de simplesmente prender o ar, perseverança é a arte de lentamente, calmamente, respirar, ao mesmo tempo que você armazena ar em seus pulmões. A menos que possa encontrar um equilíbrio entre as duas coisas, será difícil escrever romances profissionalmente por longo período. Continuando a respirar enquanto segura o fôlego." (MURAKAMI, 2018: 70).

Estas duas disciplinas, ao contrário do talento, só podem ser adquiridas por meio de treinamento: "Você aprenderá naturalmente a ter tanto concentração quanto perseverança quando sentar todo o dia diante da sua escrivaninha e treinar a mente a se concentrar em uma coisa só.” (MURAKAMI, 2018: 70). Este treinamento é um exercício de paciência, mas é esta paciência, esta persistência que "expandirá os limites do que é capaz de fazer.” (MURAKAMI, 2018: 70). Por isso é preciso treinar os processos físicos e mentais da escrita, para aumentar a concentração, a perseverança - uma resistência física necessária para aumentar, tranquilamente, numa respiração compassada, a sua força de vontade.

A escrita como inscrição no corpo, trabalho sobre o corpo. Escrever como uma certa forma de respirar. É isso que distingue os iniciantes dos veteranos: a distinção entre o arfar e o respirar compassado e tranquilo. Experimentar com a escrita na aula significa trabalhar a respiração, exercitar a dicção e o estilo, treinar o corpo para ler e escrever, exercitando a cópia, a repetição, a seleção e interpretação de trechos, escrevendo, reescrevendo, encontrando um ritmo, um modo compassado e tranquilo de se relacionar com a escrita em educação. Por isso, nas primeiras aulas, se escuta o som arfante das inquietações, dos estranhamentos que provocam os textos e os processos de escrita ensaiados: os textos excêntricos, a escrita das marcas (ROLNIK, 1993), os exercícios de 
escrita e reescrita, que progressivamente se vai transformando num modo mais compassado e tranquilo de escrever.

Trata-se de lições práticas, físicas:

Até onde posso me forçar? Quanto descanso é apropriado - e quanto é demais? Até onde posso levar alguma coisa e ainda assim mantê-la decente e consistente? Quando uma coisa se torna tacanha e inflexível? Quanta consciência do mundo devo ter, e quanto devo me concentrar em meu próprio mundo interior? Em que medida devo ter confiança em minhas capacidades e quando devo começar a duvidar de mim mesmo? (MURAKAMI, 2018, p. 72).

É, como diz Murakami, um trabalho braçal, que exige pôr em ação toda a sua reserva física, muitas vezes até ao ponto da estafa. É a rotina de que fala Pedro Costa, ao referir-se ao seu cinema como trabalho, é o tempo que precisamos para que "trabalho tome realmente conta de nós" (COSTA, 2012: 86), para que o filme, a escrita, comece a comandar-nos. Criar uma mecânica que se afina e se liberta, como fazem os pintores ou os músicos. Estudar, abrir este espaço para exercitar a escrita, para que ela nos comande, tome conta de nós. O que estilhaça essa ginástica? O que mantém a abertura da leitura e da escrita?

Em 1968, numa entrevista a Claude Bonnefoy, Foucault refere que o lado sagrado da escrita nunca o fascinou e que sempre teve "para com a escrita uma desconfiança quase moral" (FOUCAULT, 2016: 36), que nunca levou muito a sério o ato de escrever e que os seus estudos literários em nada contribuíram para fomentar o gosto pela escrita, que só experimentou tardiamente. $\mathrm{O}$ que marcou essa viragem na sua relação com a escrita foi o período em que viveu na Suécia. Diz Foucault (2016, p. 38):

Nessa impossibilidade em que me encontrei de utilizar minha própria língua, percebi, em primeiro lugar, que ela tinha uma espessura, uma consistência, que não era simplesmente como o ar que se respira, uma transparência absolutamente insensivel; depois que ela tinha as suas leis próprias, seus corredores, seus atalhos, suas linhas, suas escarpas, suas costas, suas asperezas, em suma, que ela tinha uma fisionomia e formava uma paisagem onde a gente podia passear e descobrir, no desvio das palavras, ao redor das frases, bruscamente, pontos de vista que não apareciam anteriormente.

Foi essa experiência de estrangeiro que lhe permitiu perceber que poderia habitar a sua língua, reanimando-a, construindo a sua própria casa da linguagem.

Essa experiência de estranhamento em relação à sua própria língua é uma experiência que nasce, na disciplina de pesquisa em educação, da relação que vamos estabelecendo com os textos e com as leituras que vão emergindo na turma. Naquele espaço se abre a possibilidade de construção de uma casa da linguagem através da 
descoberta de que "entre prazer de escrever e possibilidade de falar, existe certa relação de incompatibilidade. Ali onde não é mais possível falar, descobre-se o encanto secreto, difícil, um pouco perigoso de escrever." (FOUCAULT, 2016: 39). A escrita como forma de habitar a pesquisa em educação, de criar uma paisagem onde seja possível passear e descobrir, de descobrir o encanto secreto, difícil e perigoso de escrever. Dessacralizar a escrita, atribuir-lhe um certo valor, que não o do sagrado, um valor mágico, e conferirlhe um certo modo de existência, esse movimento de profanação, ou a escrita como contradispositivo, de que fala Agamben (2009).

É esse desaprender dos modos acadêmicos, escolares da escrita, de que fala Gloria Anzaldúa (2000) no texto "Falando em línguas: uma carta para as mulheres escritoras do terceiro mundo". A carta é uma forma de começar novamente, através de um formato mais intimista, mais imediato, de inventar outros modos de escrita, de trazer outros corpos para a escrita, de inventar um corpo que escreve.

Começar novamente na escrita acadêmica, começar novamente na formação de professores e na pesquisa em educação, uma forma de trabalhar a partir da imprevisibilidade de continuar a "perseguir diabinhos" (ANZALDÚA, 2000). É uma forma de ligar escrita e vida, escapando ao "perigo de ser muito universal e humanitária e invocar o eterno ao custo de sacrificar o particular, o feminino e o momento histórico específico.” (ANZALDÚA, 2000: 233). No seu texto, Anzaldúa faz presente o corpo feminino que escreve, as suas hesitações, distrações, medos, sabotagens, através de uma escrita que se pretende orgânica. Essa escrita é, tal como em Foucault, um deslocamento, que "funciona quando me surpreende, quando me diz algo que reprimi ou fingi não saber" e um perigo "porque temos medo do que a escrita revela" (ANZALDÚA, 2000: 234).

Acompanhar movimentos, operar por intensidades, esse é o belo perigo da escrita. Experimentar a materialidade pura da língua, da escrita, tal como em Barthes (1989), como possibilidade de passar da lógica representativa, reprodutiva e transitiva, da ciência, para uma lógica apresentativa, produtiva e intransitiva, da escritura. Não se trata da reprodução de um modelo, de uma fórmula, mas da afirmação de uma possibilidade, de aceitar um desafio, um convite ao jogo, tensionando as formas estabelecidas através de um exercício de deslocamento sobre a língua. Nesse sentido, toda a escritura é uma escrita, mas nem toda a escrita é escritura. Praticar a escritura na formação de professores implica acolher um sujeito impuro num campo onde imperam a ciência, o saber, o rigor e a invenção disciplinada para experimentar a sua força, num saber que com ela se comprometa. "O paradigma que aqui proponho não segue a partilha das funções; não visa 
a colocar de um lado os cientistas, os pesquisadores, e de outro os escritores, os ensaístas; ele sugere, pelo contrário, que a escritura se encontra em toda a parte onde as palavras têm sabor (saber e sabor têm, em latim, a mesma etimologia)." (BARTHES, 1989: 20)

Quando Foucault fala de uma escrita sonhada, como "uma escrita descontínua, que não teria consciência do que é e que se serviria do papel em branco, ou da máquina, do porta-canetas, ou do teclado, assim, como de muitas outras coisas que poderiam ser o pincel ou a câmara. Tudo passando velozmente de um ao outro, uma espécie de estado febril ou de caos." (FOUCAULT, 2006: 86) [tradução minha] - trata-se de uma escrita mais performática, menos racionalizada e menos escolarizada -, é esse modo de desaprender certas relações instituídas com a escrita que parece estar em causa e, ao mesmo tempo, um certo sentimento de mal-estar face ao prazer da escrita, face à sua solenidade, clausura e solipsismo. Praticar uma relação com a escrita que coloca a 'verdade' do dizer no próprio movimento do escrever, no interior do gesto de escrever. Por isso, na pesquisa em educação, as condições de verdade, o rigor, não existem fora do próprio processo de pesquisa, fora do movimento e condições que a própria pesquisa e sua escrita vão instituindo. Daí a importância de explicitar pressupostos, opções, condições - de mostrar o jogo.

Se o discurso é finito e limitado, a língua é infinita, suas possibilidades são inesgotáveis. Como no texto de Calvino ou no pensamento de Foucault, é essa inesgotabilidade que nos permite continuar a escrever, onde reside a possibilidade de experimentação com a escrita e o seu apelo. Por isso escrevemos para tensionar os limites dos discursos, em qualquer campo científico, para fugir ao lugar onde eles nos querem colocar. Escrever é trabalhar com esses limites, fugindo a toda a identificação, é não ter mais rosto, como diz Foucault numa das suas entrevistas (FOUCAULT, 2016).

Quando Foucault diz que "nunca o pesado volume do corpo chega a se desdobrar na superfície do papel, nunca passamos para esse universo de duas dimensões, para essa linha pura do discurso, nunca chegamos a nos fazer finos e sutis o bastante para não sermos nada mais que a linearidade de um texto, e, no entanto, é a isso que gostaríamos de chegar. Então, não paramos de tentar, de retomar, de nos confiscar a nós mesmos, de escorregar no funil da pena e da escrita, tarefa infinita, tarefa a que estamos fadados." (FOUCAULT, 2016: 66-67), está a referir-se à dificuldade e impossibilidade da escrita e de como o trabalho de escrever se constitui a partir dessa frustação. 
Atividade paradoxal a da escrita, é nessa impossibilidade reside a possibilidade de experimentar a obrigação de escrever. Esse inacabamento que refere Calvino (1998): por mais esgotadas que estejam as histórias, por pouco que tenha restado para contar, continuamos a contar. A obrigação da escrita nasce da inevitabilidade do fracasso da tarefa - de novo Beckett (1983), no conto Worstward Ho, “Tentar outra vez. Falhar outra vez. Falhar melhor" - ou no estilhaçamento da tarefa de escrita que refere Murakami: "Enquanto escrevo, ordeno meus pensamentos. E reescrever e revisar conduz meus pensamentos por caminhos ainda mais profundos. Por mais que escreva, contudo, nunca chego a uma conclusão. E por mais que eu reescreva, nunca atinjo um destino." (MURAKAMI, 2018: 144). Praticar a paciência, praticar a inutilidade. Como continuar a fazê-lo no mundo da utilidade, da produtividade, da aceleração, da eficiência? Trabalhar a leitura e a escrita no espaço de sala de aula talvez seja ficar fechado num parêntesis, criar um espaço de clausura que é uma "suspensão intervalar de todas as coisas úteis" (COELHO, 2001: 86).

Neste paradoxo reside a possibilidade de profanação, de restituição da escrita ao uso comum na formação de professores, uma vez liberta do peso da verdade (sobre a formação, sobre o professor, sobre a escola, sobre a educação), da avaliação, da verificação e da prescrição; talvez possamos inventar outras formas de relação com a escrita que operem a partir deste entre prazer e obrigação. Ler o que se escreve, escrever o que se lê, ler para escrever, escrever para continuar a ler, inventar um corpo que escreve...

Enquanto que o texto de Murakami chama a atenção para um conjunto de regras, rotinas, repetições que preparam o corpo para o ato de escrever e para uma relação mais próxima com a escrita, no texto de Anzaldúa as marcas do corpo na escrita aparecem na forma de relações com objetos (a caneta, o papel, o vaso, a secretária, sons), com os momentos de paragem ou distração (comer, lavar a roupa), com os rituais associados à escrita (fumar um cigarro, caminhar) como prolongamentos do próprio ato de escrever. Nesta física da leitura e da escrita que ensaiamos, parar também faz parte da escrita. As interrupções da escrita são ainda a continuação da escrita. Prado Coelho (2001) fala de dois momentos que se sucedem à leitura e que a prolongam e consagram: quando o excesso do texto faz com que o leitor levante os olhos da página e, olhando a paisagem, a vê transmutada pela experiência da leitura, e o momento em que o livro ou o texto terminam, em que ficam pousados sobre a mesa, mas continuam a trabalhar no cérebro do leitor, em que o trabalho do texto ecoa no trabalho do mundo. A leitura e a escrita 
continuam a trabalhar em nós mesmo quando paramos de escrever, mesmo quando realizamos outras tarefas. O parar faz parte da escrita, o acabar não faz, talvez não faça...

\section{A aula}

Podemos pensar a aula como o espaço onde essa experiência de escrita está ligada a uma prática coletiva, ao exercício de uma maneira de pensar em comum, no qual o leitor-escritor não aparece como sujeito, mas como subjetividade em deslocamento, como experiência. O encontro que aí se dá entre professores, alunos, textos, escritas, interesses, inquietações, pode ser um espaço de discussão e problematização dos processos e práticas científicas, e não da transmissão, verificação ou normalização disciplinar.

Para tal, à figura do professor como mestre sábio se poderia contrapor a figura do artesão-experimentador que, numa relação de igualdade com os seus alunos, pode ensaiar, através da explicitação dos seus métodos e processos de pensamento e pesquisa, formas de trabalhar em conjunto na desocultação dos processos de produção científica (Ó, 2019). A potência desse encontro reside na possibilidade de construção de uma relação de reciprocidade no exercício de composições, combinações, comparações, observações em torno de questões de interesse.

Exercitar em conjunto experiências de leitura, de escrita, de pesquisa, de formação, sem procurar agarrar, fechar, explicar, mas abrir a pesquisa, a formação, ao intempestivo, ao acontecimento, ao que opera a partir de um fora - o texto, o que está fora do texto -, do que nos afeta, um outro corpo pode se constituir nesse encontro, suspendendo o hífen que separa ensino-aprendizagem (GONÇALVES, 2019; GONÇALVES et al., 2017). Esse encontro polifónico que emerge das leituras e escritas em conjunto se dá pelo tateio que abre a possibilidade de invenção de um corpo que escreve, "não através da retórica, mas com sangue, pus e suor (ANZALDÚA, 2000: 235), voltado para o mundo e para a vida. Ensinar e aprender remeteriam para esse exercício recíproco na aula, para a potência dos corpos imersos em tal tarefa. Esta reciprocidade está relacionada com a possibilidade de criar uma ciência alegre - a gaia ciência de que fala Nietzsche -, de experimentar um saber ligado ao prazer - como Foucault nos fala em suas entrevistas (Ó, 2019).

A aula como espaço, com seu ritmo próprio, seus rituais, seus materiais, seus exercícios. Um espaço de exposição, de “tornar-se responsável pelo que se diz, de colocar o corpo, a presença inteira do corpo, ao que se faz e ao que se diz" (LARROSA, 2018: 
72), uma 'cápsula atencional', uma unidade de tempo, com seu começo e seu fim, seu próprio ritmo, que pode parecer fechada e claustrofóbica, que pode ser incômoda, estranha, mas que para aqueles que entram nela, que colocam o seu corpo na posição de estudar, se abre para revelar mundos. A aula configura tanto o corpo do professor como o dos alunos (seus gestos, movimentos, suas mãos, sua posição), convoca uma presença que implica reciprocidade, responsabilidade, resposta e também requer uma renovação das formas discursivas, da fala e da escuta, dos corpos.

Barthes (1989: 45) fala, a partir da sua experiência como professor, de um processo em que passou por várias fases: de ensinar o que se sabe, de ensinar o que não se sabe, que identifica como pesquisa, e de "uma outra experiência, a de desaprender, de deixar trabalhar o remanejamento imprevisível que o esquecimento impõe à sedimentação dos saberes, das culturas, das crenças que atravessamos.”. Manter o pensamento vivo implica praticar o esquecimento, desaprender, esse é um método de desprendimento assente numa prática de escrita entendida como fragmentação e na fala entendida como digressão, excursão, que implica uma renovação das práticas discursivas que, muitas vezes, tornam o ensino opressivo. A aula é o espaço onde essa renovação pode acontecer, onde o jogo pode ser inventado.

A aula como espaço de convite ao jogo, esse teimar e deslocar-se que constitui seu método, um espaço de estudo, em vez de um lugar de aprendizagem (INGOLD, 2018; BIESTA, 2013), um lugar de encontro, em vez de um espaço de isolamento. Se, como afirma Ingold (2018), o estudo não é uma atividade solitária, se é algo que fazemos em conjunto, a aula seria o espaço onde o estudo acontece, onde pensamos, lemos, escrevemos juntos, onde somos tocados, impregnados pelos outros, onde criamos um comum a partir de coisas, interesses, exercícios que realizamos em conjunto. O estudo é um entre que abre a possibilidade de criar mundos, de estar presentes coletivamente uns frente aos outros e frente às coisas, não aos objetos, trazidas à nossa atenção.

Ao contrário de uma formação entendida como treino, a formação inventiva requer participação, num processo em que estudantes e professores partilham um interesse e se dispõe a ser transformados por ele, num processo de comunhão e variação, de atenção e resposta, em que todos estão pacientemente e igualmente envolvidos. Barthes (1987) atribui ao professor a atividade de pesquisar e de falar, "prazerosamente de sonhar a sua pesquisa" (p. 9); esse sonho é um sonho coletivo, é um jogo que se inventa no movimento de estar juntos em torno de questões de interesse. Para Barthes (1987), o ensino como método é fantasmático, na medida em que ele é uma miragem, uma 
preparação infinita e infinitamente expansiva, e é como miragem que ele deve permanecer. Não há transmissão, apenas criação, uma performance de experimentação que permite vivenciar em conjunto a abertura, inacabamento e infinitude dos processos de pesquisa.

Ou alguém trabalha, pesquisa, produz, reúne, escreve diante dos outros; ou todos se incitam, se chamam, põem em circulação o objeto a produzir, o processo a compor, que passam assim de mão em mão, suspensos ao fio do desejo, tal como o anel no jogo que passa o anel"; "a investigação nunca é mais do que o conjunto das pessoas que buscam (que se buscam?) (BARTHES, 2004b: 412-423).

A recusa do ensino como transmissão e explicação, a desconfiança das relações pedagógicas baseadas na hierarquia estabelecida a partir de uma determinada relação com o saber, é comum tanto aos autores do chamado 'pós-estruturalismo', como Foucault, Barthes ou Deleuze, como a autores mais recentes, como Ingold, Biesta ou Masschelein e Simons que, inspirados por eles, têm trazido estas discussões para o campo da educação, questionando que relação pedagógica se torna possível a partir destas perspetivas.

Praticar a relação de estar junto no espaço-tempo da aula através de uma interrogação, de um movimento a partir do qual o pensamento vai se desdobrando, partindo do princípio da igualdade (RANCIÈRE, 2011), coloca professor e estudantes ao serviço da tarefa de produção e exteriorização do pensamento e não da aprendizagem ou da profissionalização. Trata-se, como propõe Dias (2019: 27), de "uma prática que se propõe manter vivo um campo problemático, afirmando para os que a praticam a importância de se deslocar e se transformar, não seguindo as pegadas do mestre, mas procurando, em comum, desindividualizar processos e propor práticas coletivas."

Uma formação inventiva de professores, que procura operar a partir "da ligação estreita entre conhecer e viver, entre formação e invenção" (DIAS, 2019: 13), que opere a partir da promoção de experiências de estudo que tensionem o que está posto, ensaiando relações outras entre leitura e escrita, ciência e invenção, ensino e aprendizagem, é uma (im)possibilidade na qual podemos persistir, criando um espaço-tempo em que estes exercícios aconteçam onde o começar não seja um acabar, mas um recomeçar incessante, em conjunto, em torno de questões e inquietações que nos (co)movem. Para que na sala de aula irradie a aventura difícil e perigosa de ler e escrever.

\section{Acabar?}


As questões que fui trazendo ao longo do texto sobre a leitura e a escrita na formação de professores emergem da minha experiência como professora das disciplinas relacionadas com a pesquisa em educação no curso de pedagogia. No campo da pesquisa em educação e, mais concretamente, da formação de pesquisadores em educação, tem predominado uma relação instrumental entre leitura, escrita e pesquisa (FURLONG e HODGSON, 2016), principalmente no que se refere aos manuais de metodologia da pesquisa em educação. Privilegiam-se, muitas vezes, os rigores do método, da forma e dos resultados, em detrimento de uma relação mais viva, intensa e aberta com os interesses, questões e processos e pesquisa. Por isso, recuperar a centralidade da leitura e da escrita e dos modos coletivos pensar e fazer a pesquisa se constitui como uma possibilidade de continuar a ler, escrever e pensar na universidade, para além dos modos de avaliação, verificação, produção e reprodução do conhecimento que comumente lhe estão associados. Para tal, importa que, tanto na pesquisa como na formação de professores, de um modo geral, se possam criar espaços e condições para que outras relações com a leitura, com a escrita, com a formação possam acontecer e se constituir coletivamente. $\mathrm{O}$ que se ensaia na disciplina de pesquisa em educação é uma física da leitura e da escrita que trabalha com a circularidade, o entre dois, com a inutilidade dos processos de formação em pesquisa em educação.

Murakami afirma:

Paro todo o dia bem no momento em que sinto que posso escrever mais. Feito isso, o dia de trabalho seguinte transcorre surpreendentemente bem [...] Para seguir em frente é preciso manter o ritmo. Isso é o mais importante em projetos de longo prazo. Assim que você estabelece o ritmo, o resto vem a reboque. O problema é conseguir fazer com que a roda fique girando a uma determinada velocidade - chegar a esse ponto exige o máximo de concentração e esforço de que a pessoa é capaz. (MURAKAMI, 2018: 12)

Trabalhar a leitura e a escrita para que a exaltação dure até ao dia seguinte, que a roda fique girando, e aí recomeçar, ler, reler, escrever, reescrever...

Alguns elementos que me têm permitido fazer a roda girar e mantê-la girando nas aulas de pesquisa em educação são:

a) Trabalhar o ritmo da leitura e da escrita, suas vibrações, oscilações, emergências, rupturas, suas costuras;

b) Trabalhar a temporalidade própria da leitura e da escrita, o tempo lento, o tempo da hesitação, do recomeço, da reescrita, buscando certas formas de ler e de escrever que instaurem uma outra espacialidade/temporalidade em que a 
concentração, a atenção sejam possíveis, escapando aos dispositivos habituais da leitura e da escrita na atualidade, assim como a certos procedimentos de pesquisa: a observação, a análise, a experimentação;

c) Criar uma casa para a leitura e a escrita: a aula, a pesquisa, a formação;

d) Inscrever no próprio corpo, através da leitura e da escrita, a história de outros corpos: um corpo-voz, um corpo-escuta;

e) Converter o acaso da leitura e da escrita em destino: uma escrita viva, encarnada, vibrante e reverberante;

f) Através da leitura suspender-se no limiar do acontecimento: e aí levantar os olhos do texto - a leitura e a escrita como transformação do sujeito;

Para que esse respirar compassado, de que fala Murakami, seja o do estranhamento e não o do reconhecimento, o do deslocamento e não o da identificação ou da fixidez. Para que a aula seja esse espaço de abertura do pensamento ao devir, à alteridade, sustentado no exercício da leitura e da escrita como acontecimento, como singularidade.

\section{Referências}

AGAMBEN, Giorgio. Os estudantes. Punkto, 15, 2017. Disponível em: https://www.revistapunkto.com/2017/05/estudantes-giorgio-agamben_17.html. Acesso em: 15 de Maio de 2018.

AGAMBEN, Giorgio. O que é o contemporâneo? E outros ensaios. Tradução Vinícius Nicastro Honesko. Chapecó: Editora Argos, 2009.

ANDRADE, Antonio; SANTOS, Antonio Carlos, COSTA, Ariadne; et al. Arquivo. Em: PEDROSA, Celia, KLINGER, Diana; WOLFF, Jorge; CÁMARA, Mario. Indicionário do contemporâneo. Belo Horizonte: Editora UFMG, 2018, p. 15-53.

ANZALDÚA, Gloria. Falando em Línguas: uma carta para as mulheres escritoras no terceiro mundo. Estudos Feministas, v. 8, n. 1, p. 229-236, 2000. DOI: $\underline{\text { https://doi.org/10.1590/\%25x }}$

BARTHES, Roland. O prazer do texto. São Paulo: Editora Perspetiva, 1987.

BARTHES, Roland. Aula. Trad. Leyla Perrone-Moisés. São Paulo: Cultrix, 1989.

BARTHES, Roland. O grão da voz: entrevistas. Trad. Mario Laranjeira. São Paulo: Martins Fontes, 2004a.

BARTHES, Roland. O rumor da língua. São Paulo: Martins Fontes, 2004b.

BECKETT, Samuel. Wortward Ho. Lisboa: Edição O independente, 1983.

BIESTA, Gert. Para além da aprendizagem. Educação democrática para um futuro humano. Belo Horizonte: Autêntica, 2013. 
CALVINO, Italo. Começar e acabar. Em: CALVINO, Italo. Seis propostas para o próximo milénio (Lições americanas). Tradução José Colaço Barreiros. Lisboa: Editorial Teorema, 1998.

COELHO, Eduardo P. Se o leitor escreve tu escreves. In COELHO, Eduardo Prado; GUSMÃO, Manuel. O leitor escreve para que seja possível. Lisboa: Assírio \& Alvim, 2001, p. 77-91.

COSTA, Pedro. Um melro dourado, um ramo de flores, uma colher de prata. Lisboa: Orfeu Negro, Midas Filmes, 2012.

COSTA, Pedro. Onde Jaz o teu sorriso. Lisboa: Midas Filmes, 2009.

DELEUZE, Gilles. Conversações. Rio de Janeiro: Edições 34, 1992.

DELEUZE, Gilles. Crítica e clínica. Rio de Janeiro: Edições 34, 1997.

DIAS, Rosimeri. Modos de trabalhar uma formação inventiva de professores: escrita de si, arte, universidade e escola básica. Em: DIAS, Rosimeri; RODRIGUES, Heliana (Orgs.). Escritas de si. Escutas, cartas e formação inventiva de professores entre universidade e escola básica. Rio de Janeiro: Lamparina, 2019, p. 13-36.

FOUCAULT, Michel. O Belo Perigo. Conversa com Claude Bonnefoy. Belo Horizonte: Autêntica, 2016.

FOUCAULT, Michel. Conversa com Michel Foucault (entrevista com D. Tombadori). Em: Michel Foucault, Repensar a política. Ditos \& Escritos VI. Rio de Janeiro: Forense Universitária, 2013, pp. 289-347

FOUCAULT, Michel. Soy un artificiero. In: DROIT, Roger-Pol Entrevistas con Michel Foucault. Barcelona: Paidós, 2006, p. 73-104.

FURLONG, Amanda; HODGSON, Naomi. Reading and writing for, and as, research. Em: FURLONG, Amanda; HODGSON, Naomi (Ed.). Philosophy and Theory in Educational Research. Writing in the margin. Londres e Nova York: Taylor \& Francis, 2016, p. 141-165.

GOLDMAN, Marcio. O fim da antropologia. Novos estudos - CEBRAP, 89, p. 195-211, 2011.

GONÇALVES, Teresa; BOCCHETTI, André; VALENTIM, Igor. Desviar das formas para caminhar na docência: modos colaborativos de interromper uma lógica formativa. Em: CRUZ, Giseli; OLIVEIRA, Ana; NASCIMENTO, Maria (Orgs). Ensino de didática: entre ressignificações e possibilidades. Curitiba: Editora CRV, 2017.

GONCALVES, Teresa. Pesquisa(-)Formação: composições a partir de experiências de leitura e escrita na universidade. Revista educação em questão, 57 (53), p. 1-23, e17687. 2019. DOI: https://doi.org/10.21680/1981-1802.2019v57n53ID17687

INGOLD, Tim. Against transmission. Em: INGOLD, Tim. Anthropology and/as education. New York: Routledge, 2018, p. 01-19.

LARROSA, Jorge. Pesquisa. Em: LARROSA, Jorge; RECHIA, Karen $P$ de professor. São Carlos, SP: Pedro \& João Editores, 2018, p. 337-340.

LARROSA, Jorge. Universidade. Em: LARROSA, Jorge; RECHIA, Karen. $P$ de professor. São Carlos, SP: Pedro \& João Editores, 2018, p. 483-493. 
LARROSA, Jorge. Experiência e alteridade em educação. Revista reflexão e ação, v. 19, n. 2, p. 4-27, 2011. DOI: http://dx.doi.org/10.17058/rea.v19i2.2444

LARROSA, Jorge. Dar a ler, dar a pensar...quem sabe. Entre literatura e filosofia. Em: KOHAN, Walter; LEAL, Bernardina. Filosofia para Crianças em Debate. Rio de Janeiro: Vozes, 1999, p. 119-129.

LATOUR, Bruno. Primeira Carta. Em: LATOUR, Bruno. Cogitamus: seis cartas sobre as humanidades científicas. São Paulo: Editora 34, 2016, p. 9-35.

LAVAL, Christian. Foucault e a experiência utópica. In: FOUCAULT, Michel. O enigma da revolta. Entrevistas inéditas sobre a revolução iraniana. São Paulo: n-1 Edições, 2018, p. 102-142.

MASSCHELEIN, J; SIMONS, M. Em defesa da escola: uma questão pública. Belo Horizonte: Autêntica, 2013.

MURAKAMI, Haruki. O que eu falo quando eu falo de corrida. Rio de Janeiro: Alfaguara, 2018.

Ó, Jorge Ramos do. Ouvir falar o pensamento, aprender a falar o pensamento no interior da universidade: o testemunho dos "professores" Michel Certeau, Gilles Deleuze, Michel Foucault e Roland Barthes. Revista Brasileira de educação, v. 24, e240021, 2019, p. 1-24. DOI: https://doi.org/10.1590/s1413-24782019240021

RANCIÈRE, Jacques. O mestre ignorante. Cinco lições sobre a emancipação intelectual. Belo Horizonte: Autêntica, 2011.

ROLNIK, Suely. Pensamento, corpo, devir. Uma perspectiva ético/estético/política no trabalho acadêmico. Cadernos de subjetividade, São Paulo, v. 1, n. 2, 1993, p. 241-251.

\footnotetext{
${ }^{1}$ Para Barthes (1977), a escritura é o jogo, é a abertura que faz do saber uma festa, através do deslocamento sobre a língua. É a escrita do escritor que, ao contrário da lógica representativa, explicativa e comunicativa da ciência, opera numa lógica apresentativa e produtiva que permite experimentar a materialidade pura da língua. "O discurso científico acredita ser um código superior; a escritura quer ser um código total que comporte suas próprias forças de destruição. Consequentemente, só a escritura pode quebrar a imagem teológica imposta pela ciência, recusar o terror paterno espalhado pela "verdade" abusiva dos conteúdos e dos raciocínios, abrir para a pesquisa o espaço completo da linguagem, com suas subversões lógicas, o amalgamarse de seus códigos, com os seus deslizamentos, os seus diálogos, as suas paródias" (BARTHES, 2004b: 10).
} 